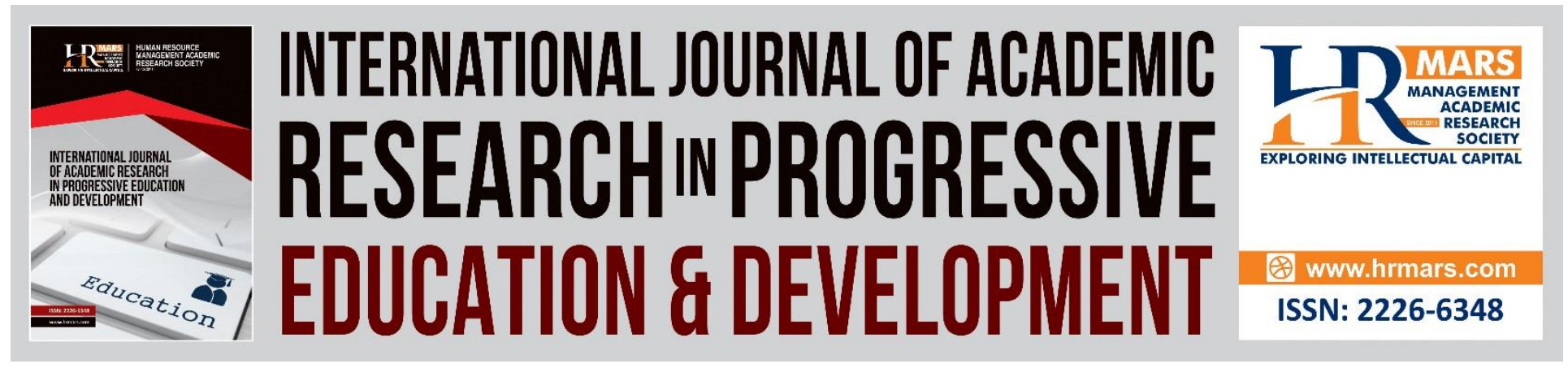

\title{
Exploratory Factor Analysis of Technostress among University Students
}

Nurul Nadia Abd Aziz, Zaidatul Nadiah Abu Yazid

To Link this Article: http://dx.doi.org/10.6007/IJARPED/v10-i3/10396

DOI:10.6007/IJARPED/v10-i3/10396

Received: 09 June 2021, Revised: 16 July 2021, Accepted: 02 August 2021

Published Online: 19 August 2021

In-Text Citation: (Aziz \& Yazid, 2021)

To Cite this Article: Aziz, N. N. A., \& Yazid, Z. N. A. (2021). Exploratory Factor Analysis of Technostress among University Students. International Journal of Academic Research in Progressive Education and Development, 10(3), 161-175.

Copyright: (C) 2021 The Author(s)

Published by Human Resource Management Academic Research Society (www.hrmars.com)

This article is published under the Creative Commons Attribution (CC BY 4.0) license. Anyone may reproduce, distribute, translate and create derivative works of this article (for both commercial and non-commercial purposes), subject to full attribution to the original publication and authors. The full terms of this license may be seen at: http://creativecommons.org/licences/by/4.0/legalcode

Vol. 10(3) 2021, Pg. 161 - 175

http://hrmars.com/index.php/pages/detail/IJARPED

JOURNAL HOMEPAGE

Full Terms \& Conditions of access and use can be found at http://hrmars.com/index.php/pages/detail/publication-ethics 


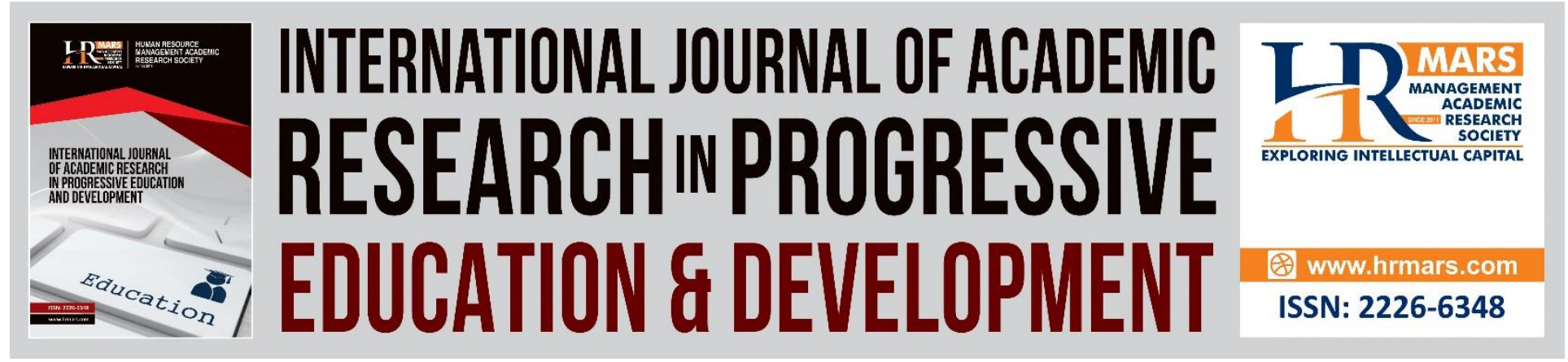

\title{
Exploratory Factor Analysis of Technostress among University Students
}

\author{
Nurul Nadia Abd Aziz, Zaidatul Nadiah Abu Yazid \\ Faculty of Business and Management, Universiti Teknologi MARA Pahang, (Raub Campus), \\ Raub, Pahang, Malaysia
}

\begin{abstract}
Research on technostress has been extensively conducted in various fields. However, research on technostress is still lacking in the context of university online learning, specifically in Malaysian public universities. This study aims to develop a technostress-related instrument that suits the context of university students. This study has adopted and adapted the instrument of technostress from the previous researchers and validated the construct using Exploratory Factor Analysis (EFA). A cross-sectional study was conducted on 338 undergraduate students in all UiTM branches in East Malaysia, using a simple random sampling method. A structured survey was used to gather the necessary information. The final analysis found that no items were omitted. Based on EFA, this study finalised the instrument to twenty-two (22) items yielding only four dimensions, i.e., techno-overload (9 items), techno-complexity (6 items), techno-insecurity (4 items), and techno-uncertainty (3 items). The high-reliability standards shown in Cronbach's alpha for each component explain that the proposed instrument is reliable and suitable for measuring technostress constructs. The results have statistically proven that these items have a high level of validity and reliability and can be used to measure technostress among university students. This instrument developed in this study can be considered for future research to measure technostress in the context of university students as a better alternative than using existing instruments used on employees in ICT organisations.
\end{abstract}

Keywords: Exploratory Factor Analysis, Instrument Development, Technostress, University Students

\section{Introduction}

Technostress refers to the stress experienced by an ICT user due to his or her inability to cope with the demands of the organisational computer usage in a healthy manner (Kader et al., 2020; Tarafdar et al., 2010). Some symptoms are identified on the people who experience technostress such as anxiety, technophobia, mental fatigue, sleep disturbances, unexplained pain, and weakened immunity. (Juškaitè, 2017). Previous studies (Hwang \& Cha, 2018; Kader et al., 2020; Ma \& Turel, 2019; Nimrod, 2018; Oh \& Park, 2016) have reported that excessive technostress can 
negatively affect individuals in terms of physical and psychological health and their social relationships.

Although many studies have discussed the negative consequences of technostress in various field, there is a lack of research on this issue in education, especially at the tertiary level. Despite having a few studies conducted in the context of education; most researchers only focus on technostress among teachers (Çoklar et al., 2016; Joo et al., 2016; Li \& Wang, 2020; Syvänen \& Mäkiniemi, 2016) and school managers (Stadin et al., 2021). University students who are mostly from the Z-Generation, are often considered digital natives and technologically savvy, thus expected to be free from technostress (Qi, 2019; Setyadi et al., 2017). As a result, the effects of technostress on psychological and behavioural strains (e.g., academic performance, satisfaction, commitment) among university students, which is crucial to online learning success (Kader et al., 2020; Qi, 2019), has been overlooked.

Since research on technostress among university students in online learning, specifically in the Malaysian public university context, is still lacking, this study aims to develop the technostress-related instrument that suits the context of university students. Initially, the tool used in this study were adopted and adapted from Li and Wang's research (2020). Li and Wang's (2020) instrument, however, has been developed to measure technostress among teachers in higher education. Therefore, the reliability of the adapted instrument needs to be analysed first before it can be used on university students in Malaysia. The current study describes the Exploratory Factor Analysis (EFA) procedure for validity, reliability, and for obtaining the genuinely feasible items for the measurement of technostress constructs for university students. This study proposes techno-overload, techno-invasion, techno-complexity, techno-insecurity, and techno-uncertainty as the core dimensions to measure technostress in the context of online learning among university students.

\section{Literature Review}

Technostress

At present, universities worldwide are eagerly modernising education systems by using ICT (Li \& Wang, 2020). These educational institutions started introducing and employing blended learning by using flipped classrooms, massive online open courses, and technology-based learning. With all these new techniques presented, instructors are expected to experience a lot of changes, especially in the teaching approaches with the students, and this leads to the increments of stress level among the educators (Li \& Wang, 2020). However, most researchers often overlook the technostress impact of ICT learning systems toward learners. The Z-generation, despite their early exposure to technologies, also face difficulties adapting to the different, new, and isolated learning sites adopted by the educators. According to previous studies (Christ-Brendemühl \& Schaarschmidt, 2020; Khedhaouria \& Cucchi, 2019; Li \& Wang, 2020; Mahapatra \& Pati, 2018; Maier et al., 2019; Stadin et al., 2021; Tarafdar et al., 2020; Wang et al., 2020), factors that cause technostress in various fields can be categorised into five groups, namely techno-overload, techno-invasion, techno-complexity, techno-insecurity, and techno-uncertainty.

Techno-overload

Techno-overload refers to a situation in which an ICT user is forced to work faster and longer (Ahmad \& Amin, 2012; Booker \& State, 2014; Hauk et al., 2019; Juškaitè, 2017; Marchiori et al., 
2019). It occurs because of the excessive information and notifications the users may receive in a short time because of the use of technology. The overflooded information and notifications into the users' smartphones could overwhelm the ICT users (Chen et al., 2019). Thus, for the current study, techno-overload is referred to as a situation where university students have to change their study habits and forced to learn faster and longer due to online learning.

As for university students, ICT has made it easier for them to communicate through smartphones because of various communication applications such as WhatsApp and telegram (Warren et al., 2020). These applications are used not only to communicate with each other but also used as a medium for discussing and informing the vital material about classes. Because of the convenient of smartphones, university students are expected to give a prompt response at any time possible (Warren et al., 2020). Most of the time, these responses require more extended time and attention. It is common in students' lives where they usually multitask, work under pressure and at the same time have to deal with a lot of information generated from learning applications, colleagues, and even their lecturers (Wang et al., 2020). The expectation to provide a reply from people around them, the notifications from social media and mobile marketing apps, not to forget the university matters reminder and information could lead to techno-overload (Wang et al., 2020). University students could avoid techno-overload by developing appropriate coping strategies to manage the situations strategically. Some researchers suggest avoiding incoming notifications and being parted with smartphones from time to time (Stadin et al., 2021).

\section{Techno-invasion}

Techno-invasion is a situation where an ICT user feels that the boundaries between work and personal contexts become blurred because they are continuously connected or can be contacted at any time (Hauk et al., 2019; Juškaitè, 2017; Tarafdar et al., 2010, 2011). The existence of technology causes ICT users to be "always exposed" so that they have the potential to be contacted anytime and anywhere. This situation causes ICT users to feel the need to stay connected (Krishnan, 2017). More recent researchers define techno-invasion as the feeling that ICT users must sacrifice their personal life (Marchiori et al., 2019). It means as technology invades personal life, more time has to be invested in learning about new technology, leading to less time spent with family or on vacation (Hwang \& Cha, 2018; Tu et al., 2005). Thus, for the current study, the researchers define techno-invasion as an invasion of student's privacy, which refers to a situation in which the learning environment and personal life of university students get merged and conflicted due to the availability of ICT and continuous connection through online learning.

In measuring technostress, this component shows mixed and inconsistent findings. For instance, a study by Ahmad et al. (2012) found that academic librarians are not heavily influenced by techno-insecurity and techno-invasion. Instead, they experience moderate stress that is most influenced by techno-uncertainty and techno-complexity. A study by Zhao et al. (2020) has also found techno-invasion to be insignificant with the challenge appraisal outcome. They argue that it has become a cultural norm of the Chinese community that most workers may be willing to work during non-working hours. However, according to Qi (2019), techno-invasion is among the most critical pressure that contributes to lower levels of academic performance. They concluded that there is pressure stemming from role ambiguity between home and school because of the use of mobile devices as a medium of learning. Some other researchers have also found that techno-invasion may affect individual productivity (Tu et al., 2005) lead to dissatisfaction with 
the application they use (Tarafdar et al., 2010), and may cause work-home conflict (Tarafdar et al., 2011).

\section{Techno-complexity}

The third type of technostress is called techno-complexity, which refers to a situation where an ICT user feels that his or her computer skills are inadequate; therefore, they have to spend a lot of time and effort to learn and understand the various features of ICT (Juškaitè, 2017). According to Tarafdar et al. (2020), techno-complexity also occurs to learners where they are forced to spend much time, and effort not only to learn but also use these learning sites, which can gradually change and be updated in a short period of time. A study by Qi (2019) concludes that most of the stress, which leads to low academic performance, comes from technology-based learning applications that are too complex for students to learn. The struggle may perhaps arise from the complexity of the features, unfamiliarity with the systems, non-mobile-friendly systems that work only in PCs and laptops. In addition, most universities lack a formal training to teach the students how to operate the official learning sites developed by the university, and students are expected to learn it by themselves. Students, which are mostly from the young generation often use the internet and technologies for entertainment purposes, not for education (Tarafdar et al., 2020).

\section{Techno-insecurity}

Techno-insecurity is a form of stress faced by ICT users due to the existence of new ICT or the presence of other colleagues who are better at ICT than they are. The ICT users will feel threatened with losing their jobs and will be replaced with someone more proficient in ICT. (Juškaitè, 2017). In this study, techno-insecurity is operationalised as students who feel threatened that they will be left behind in their studies and may be defeated by their peers who are better at online learning compared to them. A study by Ahmad et al (2012), reveals that employees under the age of 40 years old experience a low level of techno-insecurity because they may have already started working with existing technology and are more tech-savvy than more senior employees. This argument is supported by Hauk et al. (2019), which says that the cognitive ability of older workers will gradually decline, including their hearing ability, vision ability, and also some other fine motor skills that play an essential role to master the skills in ICT. However, furthering their studies, they find that age does not significantly correlate with the techno-insecurity itself. Instead, it does associate with the techno-overload and technouncertainty.

Some researchers such as Qi (2019) opines it is irrelevant to study and explain technoinsecurity among university students as they are generally digital natives who are born and raised in the internet era. They can be considered as ICT know-it-all regarding, or they can simply learn them faster as compared to the older generations. As a younger generation, most of the time, they have an explorative characteristic. They rarely are afraid to learn new skills, especially skills that are related to ICT, so that they are not easily be replaced by the technology (Maier et al., 2019). 
Techno-uncertainty

Techno-uncertainty is said to be the feeling of helplessness of the users regarding the ability to catch up with the technology changes (Ma \& Turel, 2019). Some researchers define technouncertainty as a situation where an ICT user hesitant and disturbed because ICT is continually changing and needs to be upgraded (Juškaite, 2017). These changes include the change and upgrading of software, hardware, applications, systems, and even the networks used (Ma \& Turel, 2019; Marchiori, Mainardes, \& Rodrigues, 2019). Ahmad et al (2012) assert that rapid and frequent changes in technology result in individuals feel a lot of uncertainty and ambiguity that can cause stress. For this study, techno-uncertainty refers to the continuous changes and upgrades of teaching methods using online learning, which might cause disruption and uncertainty to students as they must continuously equip themselves with these methods.

A study by Qi (2019) thinks that techno-uncertainty will not be a critical issue towards the university students, since they are born in the internet era and already familiar with all the technology. Nevertheless, the main points would be regarding the amount of workload because of the handiness of the mobile technology that could be invading the personal lives of students no matter where and what the time is. In a study conducted by Ma and Turel (2019), they discover that techno-uncertainty is mostly found among the female workers who have been working and using the same technologies over a long period compared to the male workers. However, it is proved in a study by Ahmad et al. (2012) that no matter what is the level of their technostress is, it will not affect the level of the users' commitment.

\section{Methodology}

In order to develop valid and reliable measurements for technostress construct among university students in Malaysian public universities, this study uses a cross-sectional research design. The population was the undergraduate students in Universiti Teknologi MARA (UiTM), Malaysia. This study selected 338 undergraduate students using simple random sampling. Data were analysed using IBM SPSS Statistics 25.0 software. The Kaiser-Meyer-Olkin (KMO) test and Bartlett's Test of Sphericity were conducted to measure the suitability of the sample data before the extraction or formation of components was performed using Exploratory Factor Analysis (EFA). In practice, the EFA is a factor analysis technique to assess the "belongingness" of items to specific components in a construct. EFA is used to explore the data and provide information on the best number of components needed to represent the data (Hair et al., 2011). The implementation of EFA in selecting items can reduce the number of irrelevant items. After that, the Cronbach's alpha internal consistency value for the technostress components was carried out to test the reliability of the instrument.

\section{Results and Discussion}

In this study, there were five dimensions and 22 items for the technostress construct, which was adapted from the study by Wang and Li (2020). Among 22 adapted items of technostress construct, seven items belong to the techno-overload (TO) dimension, two items belong to the techno-invasion (TIV) dimension, six items belong to the techno-complexity (TC) dimension, four items belong to the techno-insecurity (TIS) dimension, and three items belong to technouncertainty (TU) dimension. The mean and standard deviations of each item of technostress construct are, therefore, presented as follows: 
Descriptive Analysis

Table 1

This table shows the descriptive analysis result that is conducted to measure the items for technostress.

\begin{tabular}{|c|c|c|c|}
\hline & Item statements & Mean & $\begin{array}{l}\text { Std. } \\
\text { Deviation }\end{array}$ \\
\hline T01 & $\begin{array}{l}\text { I have to do more work than I can handle due to the } \\
\text { implementation of online learning. }\end{array}$ & 7.78 & 1.92 \\
\hline TO2 & $\begin{array}{l}\text { I have to work with very tight time schedules due to the } \\
\text { implementation of online learning. }\end{array}$ & 7.62 & 1.97 \\
\hline TO3 & I have to change my study habit to adapt to online learning. & 8.37 & 1.76 \\
\hline TO4 & $\begin{array}{l}\text { I have a higher workload because of the increased complexity of } \\
\text { online learning. }\end{array}$ & 7.98 & 1.82 \\
\hline TO5 & I have less free time due to the implementation of online learning. & 7.60 & 2.12 \\
\hline TO6 & $\begin{array}{l}\text { I have to be in touch with my work even during vacation because } \\
\text { of online learning. }\end{array}$ & 8.25 & 1.86 \\
\hline TO7 & $\begin{array}{l}\text { I have to work much faster due to the implementation of online } \\
\text { learning. }\end{array}$ & 8.11 & 1.87 \\
\hline TIV1 & $\begin{array}{l}\text { I have to sacrifice my vacation and weekend time to keep current } \\
\text { on the updates and new requirements of online learning. }\end{array}$ & 7.93 & 2.16 \\
\hline TIV2 & I feel my personal life is being invaded by online learning. & 7.60 & 2.25 \\
\hline TC1 & $\begin{array}{l}\text { I often find online learning too complicated for me to understand } \\
\text { it well. }\end{array}$ & 7.39 & 2.10 \\
\hline TC2 & $\begin{array}{l}\text { I often find online learning too complicated for me to use it } \\
\text { effectively. }\end{array}$ & 7.21 & 2.06 \\
\hline TC3 & $\begin{array}{l}\text { The high complexity of online learning causes me to doubt its } \\
\text { usefulness and practicality in education. }\end{array}$ & 7.08 & 2.17 \\
\hline TC4 & $\begin{array}{l}\text { I do not have adequate knowledge of online learning to complete } \\
\text { my homework satisfactorily. }\end{array}$ & 6.88 & 2.24 \\
\hline TC5 & $\begin{array}{l}\text { I need to spend a considerable amount of time and effort to use } \\
\text { online learning effectively. }\end{array}$ & 7.88 & 1.91 \\
\hline TC6 & $\begin{array}{l}\text { I do not find enough time to study and upgrade my technology } \\
\text { skills to meet the needs of online learning. }\end{array}$ & 7.14 & 2.24 \\
\hline TIS1 & $\begin{array}{l}\text { I am threatened by peers who have more vital online learning } \\
\text { skills. }\end{array}$ & 6.59 & 2.51 \\
\hline TIS2 & $\begin{array}{l}\text { I do not share my knowledge regarding online learning with my } \\
\text { peers for fear of being accused of cheating. }\end{array}$ & 5.53 & 2.56 \\
\hline TIS3 & $\begin{array}{l}\text { I am threatened by peers who know more about online learning } \\
\text { than I do. }\end{array}$ & 5.79 & 2.69 \\
\hline TIS4 & $\begin{array}{l}\text { I am threatened by peers who quickly adapt to the online learning } \\
\text { environment than I do. }\end{array}$ & 6.28 & 2.79 \\
\hline TU1 & $\begin{array}{l}\text { There are frequent upgrades in online learning we use in our } \\
\text { university. }\end{array}$ & 6.48 & 1.90 \\
\hline
\end{tabular}




\begin{tabular}{|l|l|l|l|}
\hline TU2 & $\begin{array}{l}\text { There are constant changes to the functionalities in online learning } \\
\text { we use in our university. }\end{array}$ & 6.42 & 1.96 \\
\hline TU3 & $\begin{array}{l}\text { Our university regularly replaces one teaching and learning } \\
\text { method with another. }\end{array}$ & 6.07 & 2.05 \\
\hline
\end{tabular}

The evaluation items related to technostress (Table 3 ) reveal that, in general, the average obtained is high, indicating that the problem appears to be very relevant in the opinion of the population being studied. For example, the highest mean is detected in the construct of technooverload, which is $M=8.37$ (TO3), followed by $M=8.25$ (TO6) and $M=8.11$ (TO7). The university students stated that they had to change their habits to adapt to online learning; they needed to use their vacation time to study online and worked faster due to the implementation of online learning. The degree of discrepancy in the responses to these three items was also low, i.e., SD = $1.76, \mathrm{SD}=1.86$, and $\mathrm{SD}=1.87$, respectively.

Similarly, university students did report facing many difficulties with the complexity of online learning. Among the items that compose the construct, what stands out is that they need to spend a lot of time and effort to use online learning effectively $(M=7.88, S D=1.91)$. In contrast, the item with the lowest impact was the opinion that they do not have enough knowledge of online learning to complete their homework satisfactorily $(M=6.68, S D=2.24)$. Thus, the opinion of Wang and Li (2020), who said the younger generation is tech-savvy, may not be accurate because it contradicts with the population under study, in which is all of them are teenagers from the $Z$ Generation.

The result of the techno-uncertainty construct suggests that university students facing stress due to frequent upgrades in online learning $(M=6.48, S D=1.90)$, and constant changes to the functionalities in online learning $(M=6.42, S D=1.96)$. Finally, the techno-insecurity construct presents the lowest mean among the four technostress constructs. That is, the university students stated that they are threatened by peers with better online learning skills $(M=6.59, S D$ $=2.79)$. Another statement is reaching a value slightly higher than neutrality $(M=5.53)$, and a low degree of convergence of opinions $(S D=2.56)$. It refers to the opinion that the university students do not share their knowledge regarding online learning with peers for fear of being accused of cheating.

Bartlett's Test and KMO Value

Table 2

The table shows the Bartlett's Test and KMO Value

\begin{tabular}{|l|l|l|}
\hline \multicolumn{2}{|l|}{ KMO and Bartlett's Test } \\
\hline Kaiser-Meyer-Olkin Measure of Sampling Adequacy. & .94 \\
\hline Bartlett's Test of Sphericity & Approx. Chi-Square & 12492.92 \\
\cline { 2 - 3 } & df & 231 \\
\cline { 2 - 3 } & Sig. & .00 \\
\hline
\end{tabular}


DEVELOPMENT

Vol. 10, No. 3, 2021, E-ISSN: 2226-6348 @ 2021 HRMARS

Table 2 shows the Kaiser-Meyer-Olkin (KMO) value of 0.94 is excellent as it exceeds the general acceptance index of KMO of 0.60 . Table 2 also presents the significance value of Bartlett's Test of Sphericity is 0.00 , which meets the required significance value of less than 0.005 (Bahkia et al., 2019). The value indicates that these items are sufficient for intercorrelation. It also suggests that the data and sample size was adequate and appropriate to proceed further with the reduction procedure.

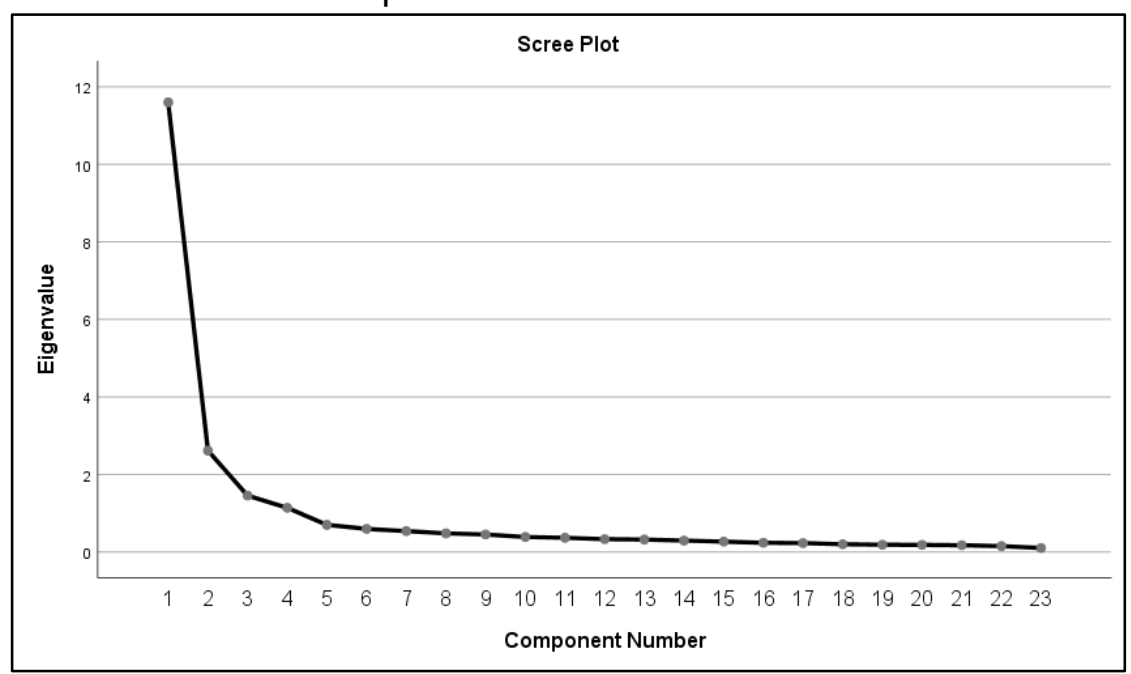

Figure 1. Scree plot indicating the number of factors to retain in principal component analysis.

Inspection of the scree plot of eigenvalues was performed to determine the point at which the slope of the curve flattens. The purpose is to indicate the number of factors that should be kept. Figure 1 shows that four main factors contribute significantly to the overall variance change in the technostress component. An inspection in Figure 1 indicates a significant drop of variance after the fourth component, thus suggesting that only four strong factors exist. The result shows that it starts from the fifth factor; the eigenvalues drop under 0.50. The low eigenvalues mean that it does not contribute much to explaining differences in variables and can be ignored. Hence, one factor should be eliminated as failing to meet the minimum load value criteria of 0.50 set by the researchers and did not contribute to the factor structure.

Table 3

The table shows the EFA procedures on four components of the technostress construct that has been extracted for further analysis

\begin{tabular}{|l|l|l|l|}
\hline \multirow{2}{*}{ Component } & \multicolumn{3}{|l|}{ Rotation Sums of Squared Loadings } \\
\cline { 2 - 4 } & Total & \% of variance & Cumulative \% \\
\hline 1 & 6.70 & 30.43 & 30.43 \\
\hline 2 & 3.87 & 17.57 & 48.00 \\
\hline 3 & 3.15 & 14.33 & 62.33 \\
\hline 4 & 2.55 & 11.60 & 73.92 \\
\hline
\end{tabular}

Factors were extracted using the primary axis factorisation method with Varimax Rotation with Kaiser Normalization criteria of eigenvalues 1 or greater. The selection of Varimax rotation is to ensure that the grouping of factors is not correlated. Table 3 shows the EFA procedures have extracted four components of the technostress construct and would be 
considered for further analysis. The eigenvalues ranged between 2.55 and 6.70 . The first component with an eigenvalue of 6.70 contributes to $30.43 \%$ of the variance. The component 2 contribute $17.57 \%$ (eigenvalue $=3.87$ ), component 3 contribute $14.33 \%$ (eigenvalue $=3.15$ ), and component 4 contribute $11.60 \%$ (eigenvalue $=2.55$ ). The four components collectively accounted for $73.92 \%$ of the variance, which is acceptable since it is higher than $60 \%$ of the variance (Bahkia et al., 2019).

The results in Table 4 also shows that the EFA procedure has extracted four components. Each component has a certain number of items with their respective factor loading. In this study, the only item having factor loading above 0.60 will be retained since it indicates the usefulness of items in measuring the particular construct (Bahkia et al., 2019). As a result, the rotated component matrix shows that all 22 items have a factor loading above 0.60. However, two items from techno-invasion construct (TIV1 and TIV2) indicate the factor loading of the items overlapped with another construct, namely techno-overload. Technoinvasion items, which are "I have to sacrifice my vacation and weekend time to keep current on the updates and new requirements of online learning" (TIV1) and "I feel my personal life is being invaded by online learning" (TIV2), indicate that university students have to sacrifice their free time and vacation to complete online learning.

Therefore, it makes sense that the construction of techno-invasion items overlaps with the techno-overload component. These results are parallel with the findings of Wang and Li (2020). They also found techno-invasion items overlapping with the techno-overload component when the instrument was tested on the university teachers. Since both items (TIV1 and TIV2) have a high factor loading, which is more than 0.70 , the current researchers decided to retain them and included in the techno-overload component. In the end, the finalised instrument consists of four components, comprising nine items for techno-overload, six items for techno-complexity, four items for techno-insecurity, and three items for technouncertainty. 
INTERNATIONAL JOURNAL OF ACADEMIC RESEARCH IN PROGRESSIVE EDUCATION AND

DEVELOPMENT

Vol. 10, No. 3, 2021, E-ISSN: 2226-6348 @ 2021 HRMARS

Table 4

The table shows the results of EFA procedure has extracted four components of technostress

\begin{tabular}{|c|c|c|c|c|}
\hline \multicolumn{5}{|c|}{ Rotated Component Matrix } \\
\hline & \multicolumn{4}{|c|}{ Component } \\
\hline & 1 & 2 & 3 & 4 \\
\hline T01 & .72 & & & \\
\hline TO2 & .81 & & & \\
\hline TO3 & .71 & & & \\
\hline TO4 & .82 & & & \\
\hline TO5 & .75 & & & \\
\hline T06 & .82 & & & \\
\hline TO7 & .83 & & & \\
\hline TIV1* & .76 & & & \\
\hline TIV2* & .71 & & & \\
\hline TC1 & & .81 & & \\
\hline TC2 & & .81 & & \\
\hline TC3 & & .75 & & \\
\hline TC4 & & .75 & & \\
\hline TC5 & & .67 & & \\
\hline TC6 & & .63 & & \\
\hline TIS1 & & & .76 & \\
\hline TIS2 & & & .67 & \\
\hline TIS3 & & & .88 & \\
\hline TIS4 & & & .84 & \\
\hline TU1 & & & & .83 \\
\hline TU2 & & & & .87 \\
\hline TU3 & & & & .82 \\
\hline
\end{tabular}

Note: Component 1 = Techno-Overload; Component 2 = Techno-Complexity; Component 3 = Techno-Insecurity; Component 4 = Techno-Uncertainty; ${ }^{*}$ items factor-loading overlapped with techno-overload component

Reliability

Reliability quantifies the measurement error. Its refers to the stability, equivalence, and consistency of the instrument. It means that the respondent will get the same score from the instrument if the trait to be measured does not change even if measured many times with the same instrument. Thus, the researchers need to compute Cronbach's alpha to test the internal consistency to determine the reliability of the retained items in measuring the technostress construct. The Cronbach's alpha value must be greater than 0.70 (Bahkia et al., 2019) to indicate that the element achieves internal reliability. The four components that measure the technostress construct, with their respective Cronbach's alpha values are observable in Table 5. 
INTERNATIONAL JOURNAL OF ACADEMIC RESEARCH IN PROGRESSIVE EDUCATION AND

DEVELOPMENT

Vol. 10, No. 3, 2021, E-ISSN: 2226-6348 @ 2021 HRMARS

Table 5

The table shows the internal reliability coefficient for assumed factors

\begin{tabular}{|l|l|l|}
\hline Name & Number of items & Cronbach's Alpha \\
\hline Techno-overload & $9 *$ & 0.94 \\
\hline Techno-complexity & 6 & 0.93 \\
\hline Techno-insecurity & 4 & 0.88 \\
\hline Techno-uncertainty & 3 & 0.89 \\
\hline
\end{tabular}

Note: *including two items from techno-invasion construct (TIV1 and TIV2)

The Cronbach's alpha for each component shows a high-reliability standard, which is higher than the threshold value of 0.70 . The Cronbach's alpha values for the four components of the technostress construct are 0.94 for component 1 (techno-overload), 0.93 for component 2 (techno-complexity), 0.88 for component 3 (techno-insecurity), and 0.89 for component 4 (techno-uncertainty). It implies that the extracted components with their respective items are appropriate and reliable to measure the technostress construct. Hence, future researchers are recommended to use those items to measure technostress constructs, especially in the context of online learning among university students.

\section{Conclusion}

Current research has contributed to existing knowledge about the measurement of technostress constructs, especially in online learning among university students. The EFA results form a configuration extracting four technostress components: techno-overload, techno-complexity, techno-insecurity, and techno-uncertainty, measured by the 22 items. The technostress instrument tested also achieves Bartlett's Test of Sphericity significance value of less than 0.005 , exceeding the general acceptance index of KMO value of 0.60 , and factors loading above the minimum threshold of 0.60 (Bahkia et al., 2019).

The results obtained from this study also show that technostress instruments have completed measurement characteristics and met various dimensions. The Cronbach's alpha values for this technostress instrument is between 0.88 to 0.94 , representing a high-reliability value. The result corresponds to the findings of the previous study, which has found that similar instruments used on university teachers have a Cronbach's alpha value above 0.70 (Wang \& Li, 2020). Thus, the technostress instrument developed by the current study is accurate, easy to understand, and equivalent to the original version.

Therefore, this study suggests that technostress measurements are reliable, and this validated instrument is consistent and stable across samples. This instrument can be considered for future research to measure technostress in the context of university students as a better alternative than using existing instruments used on employees in ICT organisations. However, further research needs to be done on a sample of students from other universities to validate the instrument.

Some study limitations may affect outcomes and generalisations. The survey has been conducted in higher education institutions, which produce results limited in the context of education in Malaysia by selecting UiTM undergraduate students and not applied in various public universities in Malaysia. While the data was collected, Malaysia was enforcing the Movement Control Order (MCO) due to the outbreak of the Covid-19 pandemic. Thus, these students had to totally accept and use the online learning system for the first time during their studies at the university. Therefore, students may experience higher stress as they have 
not yet been able to fully adapt to the online learning system. Thus, interviews and focus groups with students are strongly encouraged to interpret the actual stressful situations.

\section{Acknowledgement}

This study is self-financing and is not sponsored by any funding agencies.

\section{References}

Ahmad, U. N. U., \& Amin, S. M. (2012). The Dimensions of Technostress among Academic Librarians. Procedia - Social and Behavioral Sciences, 65(ICIBSoS), 266-271. https://doi.org/10.1016/j.sbspro.2012.11.121

Ahmad, U. N. U., Amin, S. M., \& Ismail, W. K. W. (2012). The Relationship Between Technostress Creators and Organisational Commitment Among Academic Librarians. Procedia - Social and Behavioral Sciences, 40(6), 182-186. https://doi.org/10.1016/j.sbspro.2012.03.179

Bahkia, A. S., Awang, Z., Afthanorhan, A., Ghazali, P. L., \& Foziah, H. (2019). Exploratory factor analysis on occupational stress in context of Malaysian sewerage operations. AIP Conference Proceedings, 2138(August). https://doi.org/10.1063/1.5121111

Booker, Q. E., \& State, M. (2014). a Model for Testing Technostress in the Online Education Environment: an Exploratory Study. Issues in Information Systems, 15(2), 214-222.

Chen, J. V., Tran, A., \& Nguyen, T. (2019). Understanding the discontinuance behavior of mobile shoppers as a consequence of technostress: An application of the stress-coping theory. Computers in Human Behavior, 95(August 2018), 83-93. https://doi.org/10.1016/j.chb.2019.01.022

Christ-Brendemühl, S., \& Schaarschmidt, M. (2020). The impact of service employees' technostress on customer satisfaction and delight: A dyadic analysis. Journal of Business Research, 117(June), 378-388. https://doi.org/10.1016/j.jbusres.2020.06.021

Çoklar, A. N., Efilti, E., Şahin, Y. L., \& Akçay, A. (2016). Investigation of techno-stress levels of teachers who were included in technology integration processes. Turkish Online Journal of Educational Technology, 2016(NovemberSpeciallssue), 1331-1339.

Hair, J. F., Ringle, C. M., \& Sarstedt, M. (2011). PLS-SEM: Indeed a Silver Bullet. The Journal of Marketing Theory and Practice, 19(2), 139-152.

Hauk, N., Göritz, A. S., \& Krumm, S. (2019). The mediating role of coping behavior on the agetechnostress relationship: A longitudinal multilevel mediation model. PLOS ONE, 14(3), 1-23. https://doi.org/10.1371/journal.pone.0213349

Hwang, I., \& Cha, O. (2018). Examining technostress creators and role stress as potential threats to employees' information security compliance. Computers in Human Behavior, 81, 282-293. https://doi.org/10.1016/j.chb.2017.12.022

Joo, Y. J., Lim, K. Y., \& Kim, N. H. (2016). The effects of secondary teachers' technostress on the intention to use technology in South Korea. Computers and Education, 95, 114-122. https://doi.org/10.1016/j.compedu.2015.12.004

Juškaitè, V. (2017). ICT use in the carers' work: Technostress. Medical Physics in the Baltic States, 13(November), 56-61.

Kader, M. A. R. A., Aziz, N. N. A., \& Dangi, M. R. M. (2020). Mediating effects of English proficiency on the association between religiosity commitment, study habits, self-study concept, and perceived stress. Humanities \& Social Sciences Reviews, 8(5), 219-232.

Khedhaouria, A., \& Cucchi, A. (2019). Technostress creators, personality traits, and job 
burnout: A fuzzy-set configurational analysis. Journal of Business Research, 101(April), 349-361. https://doi.org/10.1016/j.jbusres.2019.04.029

Krishnan, S. (2017). Personality and espoused cultural differences in technostress creators. Computers in Human Behavior, 66, 154-167. https://doi.org/10.1016/j.chb.2016.09.039

Li, L., \& Wang, X. (2020). Technostress inhibitors and creators and their impacts on university teachers' work performance in higher education. Cognition, Technology and Work, 0123456789. https://doi.org/10.1007/s10111-020-00625-0

Ma, Y., \& Turel, O. (2019). Information technology use for work and technostress: effects of power distance and masculinity culture dimensions. Cognition, Technology and Work, 21(1), 145-157. https://doi.org/10.1007/s10111-018-0503-1

Mahapatra, M., \& Pati, S. P. (2018). Technostress Creators and Burnout. SIGMIS-CPR'18, 7077. https://doi.org/10.1145/3209626.3209711

Maier, C., Laumer, S., Wirth, J., \& Weitzel, T. (2019). Technostress and the hierarchical levels of personality: a two-wave study with multiple data samples. European Journal of Information Systems, 28(5), 496-522. https://doi.org/10.1080/0960085X.2019.1614739

Marchiori, D. M., Mainardes, E. W., \& Rodrigues, R. G. (2019). Do Individual Characteristics Influence the Types of Technostress Reported by Workers? International Journal of Human-Computer Interaction, 35(3), 218-230.

https://doi.org/10.1080/10447318.2018.1449713

Nimrod, G. (2018). Technostress: measuring a new threat to well-being in later life. Aging and Mental Health, 22(8), 1080-1087. https://doi.org/10.1080/13607863.2017.1334037

Oh, S. T., \& Park, S. (2016). A Study of the Connected Smart Worker's Techno-stress. Procedia Computer Science, 91(Itqm), 725-733. https://doi.org/10.1016/j.procs.2016.07.065

Qi, C. (2019). A double-edged sword? Exploring the impact of students' academic usage of mobile devices on technostress and academic performance. Behaviour and Information Technology, 38(12), 1337-1354. https://doi.org/10.1080/0144929X.2019.1585476

Setyadi, H. J., Widagdo, P. P., \& Susanto, T. D. (2017). Cognitive age and chronological age of the technostress that effect on satisfaction, performance, and intention of continue the use of information technology in the university. Proceeding - 2017 3rd International Conference on Science in Information Technology: Theory and Application of IT for Education, Industry and Society in Big Data Era, ICSITech 2017, 2018-Janua, 330-335. https://doi.org/10.1109/ICSITech.2017.8257134

Stadin, M., Nordin, M., Broström, A., Magnusson Hanson, L. L., Westerlund, H., \& Fransson, E. I. (2021). Technostress operationalised as information and communication technology (ICT) demands among managers and other occupational groups - Results from the Swedish Longitudinal Occupational Survey of Health (SLOSH). Computers in Human Behavior, 114(March 2020), 106486. https://doi.org/10.1016/j.chb.2020.106486

Syvänen, A., \& Mäkiniemi, J. (2016). When does the educational use of ICT become a source of technostress for Finnish teachers? Seminar.Net, 12(2).

Tarafdar, M., Maier, C., Laumer, S., \& Weitzel, T. (2020). Explaining the link between technostress and technology addiction for social networking sites: A study of distraction as a coping behavior. Information Systems Journal, 30(1), 96-124.

https://doi.org/10.1111/isj.12253

Tarafdar, M., Tu, Q., \& Ragu-Nathan, T. (2010). Impact of technostress on end-user satisfaction and performance. Journal of Management Information Systems, 27(3), 303334. https://doi.org/10.2753/MIS0742-1222270311 
Tarafdar, M., Tu, Q., Ragu-Nathan, T. S., \& Ragu-Nathan, B. S. (2011). Crossing to the dark side: Examining creators, outcomes, and inhibitors of technostress. Communications of the ACM, 54(9), 113-120. https://doi.org/10.1145/1995376.1995403

Tu, B. Y. Q., Wang, K., \& Shu, Q. I. N. (2005). Q I a N G TU, Ka N L I a N G W a N G. 48(4), 7782.

Wang, X., Tan, S. C., \& Li, L. (2020). Technostress in university students' technology-enhanced learning: An investigation from multidimensional person-environment misfit. Computers in Human Behavior, 105(November 2019). https://doi.org/10.1016/j.chb.2019.106208

Warren, L., Reilly, D., Herdan, A., \& Lin, Y. (2020). Self-efficacy, performance and the role of blended learning. Journal of Applied Research in Higher Education. https://doi.org/10.1108/JARHE-08-2019-0210

Zhao, X., Xia, Q., \& Huang, W. (2020). Impact of technostress on productivity from the theoretical perspective of appraisal and coping processes. Information and Management, 1088, 103265. https://doi.org/10.1016/j.im.2020.103265 